UCRL-ID- 122156

\title{
Pneumatic Energy Storage
}

\author{
Daniel Flowers
}

September 19, 1995

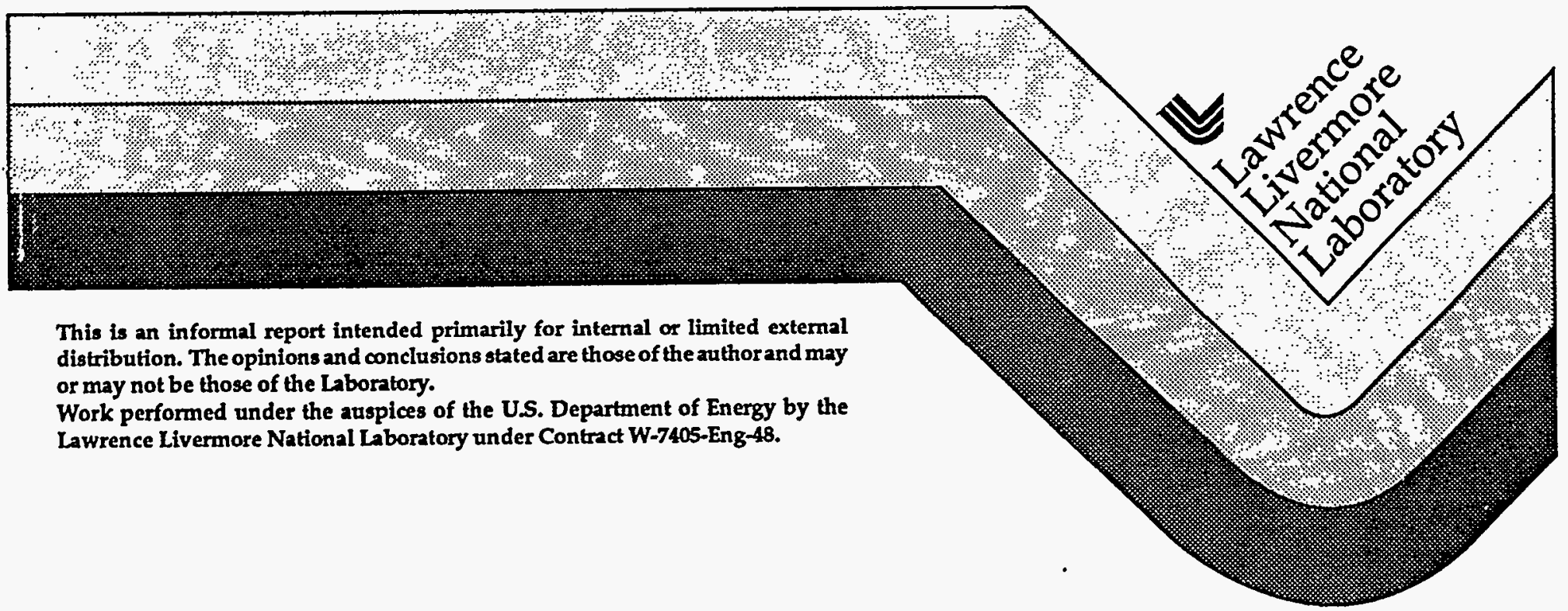

This is an informal report intended primarily for internal or limited external distribution. The opinions and conclusions stated are those of the author and may or may not be those of the Laboratory.

Work performed under the auspices of the U.S. Department of Energy by the Lawrence Livermore National Laboratory under Contract W-7405-Eng-48. 


\section{DISCLAIMER}

This report was prepared as an account of work sponsored by an agency of the United States Government. Neither the United States Government nor any agency thereof, nor any of their employees, make any warranty, express or implied, or assumes any legal liability or responsibility for the accuracy, completeness, or usefulness of any information, apparatus, product, or process disclosed, or represents that its use would not infringe privately owned rights. Reference herein to any specific commercial product, process, or service by trade name, trademark, manufacturer, or otherwise does not necessarily constitute or imply its endorsement, recommendation, or favoring by the United States Government or any agency thereof. The views and opinions of authors expressed herein do not necessarily state or reflect those of the United States Government or any agency thereof. 


\section{DISCLAIMER}

Portions of this document may be illegible in electronic image products. Images are produced from the best available original document. 


\section{Pneumatic Energy Storage}

\subsection{Introduction}

An essential component to hybrid electric and electric vehicles is energy storage. A power assist device could also be important to many vehicle applications. This discussion focuses on the use of compressed gas as a system for energy storage and power in vehicle systems. Three possible vehicular applications for which these system could be used are discussed in this paper. These applications are pneumatically driven vehicles, series hybrid electric vehicles, and power boost for electric and conventional vehicles.

One option for a compressed gas system is as a long duration power output device for purely pneumatic and hybrid cars. This system must provide enough power and energy to drive under normal conditions for a specified time or distance. The energy storage system for this use has the requirement that it will be highly efficient, compact, and have low mass.

Use of a compressed gas energy storage as a short duration, high power output system for conventional motor vehicles could reduce engine size or reduce transient emissions. For electric vehicles this kind of system could lengthen battery life by providing battery load leveling during accelerations. The system requirements for this application are that it be compact and have low mass. The efficiency of the system is a secondary consideration in this application.

There are three levels of energy storage required for three types of vehicle systems. For a series hybrid electric vehicle, the energy storage requirement is on the order of $1 \mathrm{kWh} .{ }^{1} \mathrm{~A}$ pneumatic car has been built previously, but no information on storage is given in the literature on this car. ${ }^{2.3}$ For the pneumatic vehicle, a minimum energy requirement of $7.5 \mathrm{kWh}$ has been determined using data for the GM Impact III, a very efficient electric car. ${ }^{4}$ This energy storage would give the vehicle an approximate range of 50 miles-traveling at a speed of 55 miles per hour. These vehicles, especially the series hybrid, require high turn-around efficiency, high energy per mass, and high energy per volume. In order for the system to compete with batteries, the storage system must have a turn- 
around efficiency of at least $75 \%$. An energy storage system for use as a power assist device has a storage requirement on the order of $0.1 \mathrm{kWh}$ of energy storage, which is equivalent to generating $50 \mathrm{~kW}$ for approximately 7 seconds. These three vehicle systems are considered with $0.1 \mathrm{kWh}, 1 \mathrm{kWh}$, and $7.5 \mathrm{kWh}$ energy storage capacity.

For the three applications, two possible system designs have been considered. The first system involves using a constant mass stored at high pressure. The air in the tank is allowed to expand and displace a piston which in turn displaces hydraulic fluid through a hydraulic pump. The second system considered is a high pressure constant volume tank that stores compressed gas. When power output is required the gas is expanded through turbine stages. The expanded gas is either released into the atmosphere or stored in a second constant volume tank.

The models used in this analysis are very idealized and have been developed in order to find whether for a best possible case for this kind of storage is feasible. The calculated results are optimistic.

\subsection{Pneumatic/Hydraulic System}

The system considered here is a compressed gas which is allowed to expand and displaces hydraulic fluid through a hydraulic turbine in order to get useful work from the expansion of the gas. For a specified energy storage, the mass and volume are determined. The model for this system consists of gas storage, hydraulic fluid, and pump. The pump is considered a device that can extract or add energy to the gas. There are two variations considered in this analysis, shown in Fig. 1. In the first, the system consists of a tank containing a constant mass of high pressure gas that displaces a piston as it is allowed to expand. The piston displaces hydraulic fluid through a pump. The pump outlet hydraulic fluid is forced against another piston, and that piston compresses a second mass of gas in a second tank. The second version differs only in that the pump outlet side piston is displaced against atmospheric air. While it is clear that the second version will ideally have a lower volume and weight, practical considerations (i.e. maximum pressure ratio across the hydraulic pump) may make it necessary to use the first configuration (Fig. 1(a)). The tank volume is determined in both configurations. The mass of the 
system includes that of the tanks, the gas, the hydraulic fluid, and the machinery. The assumptions used in both analysis are stated below.

1. Constant temperature (equal to ambient temperature, $300 \mathrm{~K}$ ) for the entire process that is uniformly distributed throughout the system.

2. Pressure is uniform through gas and hydraulic fluid to pump orifice

3. The gas acts as an ideal gas

4. The hydraulic fluid is incompressible

5. There is no leakage at the piston interface

\subsubsection{Volume model for pneumatic/hydraulic two tank system}

Some notation involved in the two tank analysis will first be explained. A nomenclature list is also provided. The high pressure tank is referenced as subscript ' 1 , and the low pressure tank is referenced as subscript '2.' Initial points are subscripted ' $i$ ', and final points are subscripted ' $\mathrm{f}$.' The overall work is $\mathrm{W}$, non-dimensional work, $\mathrm{W}^{*}$, the required output work, $W_{0}$, and total volume of the tanks, $V_{T}$. Other variables involve include $\mathrm{p}$, pressure in a tank, $\mathrm{n}$, moles of gas in a tank, $\alpha$, the ratio of moles in tank 1 to moles in tank 2 , and $\beta$, the ratio of the final pressure in tank 1 to the final pressure in tank 2.

The analysis is based on determining the minimum $\mathrm{V}_{\mathrm{T}}$ for a system with a required energy storage capacity for fixed initial pressures, $\mathrm{p}_{1 \mathrm{i}}$ and $\mathrm{p}_{2 \mathrm{i}}$. The two ratios, $\alpha$ and $\beta$ are varied in order to find the volumetric relations. An additional assumption required for this model is that $\alpha$ is finite. This assumption allows that the final pressure in tank 1 can be determined from the equality of the change in volume of the two tanks due to the incompressibility of the hydraulic fluid. Below are the important relations in the analysis.

$$
\begin{aligned}
& W=n_{1} R T \ln \left(\frac{p_{1 i}}{p_{i f}}\right)+n_{2} R T \ln \left(\frac{p_{2 i}}{p_{2 f}}\right) \\
& \alpha \equiv \frac{n_{1}}{n_{2}}, \quad \beta \equiv \frac{p_{1 f}}{p_{2 f}}
\end{aligned}
$$




$$
\begin{aligned}
& \mathrm{W}^{*} \equiv \frac{\mathrm{W}}{\mathrm{n}_{1} \mathrm{RT}}=\ln \left(\frac{\mathrm{p}_{1 \mathrm{i}}}{\mathrm{p}_{1 \mathrm{f}}}\right)+\frac{1}{\alpha} \ln \left(\frac{\mathrm{p}_{2 \mathrm{i}}}{\mathrm{p}_{2 \mathrm{f}}} \beta\right) \\
& \mathrm{p}_{1 \mathrm{f}}=\frac{1+\beta / \alpha}{1 / \mathrm{p}_{1 \mathrm{i}}+1 / \alpha \mathrm{p}_{2 \mathrm{i}}} \\
& \mathrm{V}_{\mathrm{T}}=\left(\frac{\mathrm{W}_{0}}{\mathrm{~W}^{*}}\right) \frac{1}{\eta_{\mathrm{P}}}\left[\frac{1}{\mathrm{p}_{1 \mathrm{f}}}+\frac{1}{\alpha \mathrm{p}_{2 \mathrm{i}}}\right]
\end{aligned}
$$

The ratio $\alpha$ must be greater than or equal to unity to minimize the work required to compress tank 2 and to minimize $p_{1 f}$ which in turn increases the work output from the gas in tank 1 . The ratio $\beta$ must be greater than or equal to unity due to the physical constraint that the process will not reverse itself.

Minimizing the volume of the system for a specified output work involves picking initial tank pressures, $p_{1 i}$ and $p_{1 f}$, and then varying the values of $\alpha$ and $\beta$. For each $\beta$ the volume is determined by varying $\alpha$.

\subsubsection{Mass estimate for pneumatic/hydraulic two tank system}

The mass of the tanks can be determined by finding the maximum volume and pressure in each tank. The relationship below is for the total tank mass where $x_{m}$ is the unit of merit for the tank material (with dimensions of length), and $g$ is the gravitational acceleration. The 2.25 in the expression is a factor of safety mandated for the tanks.

$$
\mathrm{m}_{\text {Tanks }}=2.25\left(\frac{\mathrm{n}_{1} R T}{\mathrm{x}_{\mathrm{m}} \mathrm{g}}\right)\left[\frac{\mathrm{p}_{1 \mathrm{i}}}{\mathrm{p}_{1 \mathrm{f}}}+\frac{\mathrm{p}_{2 \mathrm{f}}}{\alpha \mathrm{p}_{2 \mathrm{i}}}\right]
$$

The mass of the gas can be determined by assuming a gas to be used in the system. As air is the most available and cheap gas, each tank is assumed to filled with dry air of molar mass MM.

$$
\mathrm{m}_{\mathrm{gas}}=\mathrm{n}_{1} \mathrm{MM}\left(1+\frac{1}{\alpha}\right)
$$


The mass of hydraulic fluid displaced is determined by finding the product of the fluid density, $\rho_{h . f .}$, and the change in volume of either tank (the change in volume of each tank is equal).

$$
\mathrm{m}_{\text {h.f. }}=\rho_{\text {h.f. }} \mathrm{n}_{1} \mathrm{RT}\left(\frac{1}{\mathrm{p}_{1 \mathrm{f}}}-\frac{1}{\mathrm{p}_{1 \mathrm{i}}}\right)
$$

The pump mass includes the dry pump mass and the mass of the associated internal fluid and piping. The dry pump mass is found from manufacturers specifications, and the additional pump mass is estimated. The total mass of the system is the sum of all the associated masses.

$$
\mathrm{m}_{\text {total }}=\mathrm{m}_{\text {Tanks }}+\mathrm{m}_{\text {gas }}+\mathrm{m}_{\mathrm{h} . \mathrm{f} .}+\mathrm{m}_{\text {pump }}
$$

This does not take into account any additional mass required for mechanical support if this were stored in a vehicular system. The mass of the tanks, gas, and hydraulic fluid can be scaled linearly to the energy storage. The pump mass is assumed constant for any energy storage capacity.

\subsubsection{Volume model for pneumatic/hydraulic one tank system}

The notation used for the one tank analysis is the same as in 2.1.1, with tank 2 ignored, and the low pressure side of the pump constant at the ambient pressure, patm. The equations used to develop this system are given below. The expression for volume includes the tank volume and the volume of a hydraulic fluid receptacle on the outlet side of the turbine.

$$
\begin{gathered}
\mathrm{W}=\mathrm{n}_{1} \mathrm{RT} \ln \left(\frac{\mathrm{p}_{1 \mathrm{i}}}{\mathrm{p}_{1 \mathrm{f}}}\right)-\mathrm{n}_{1} \mathrm{RT}\left(\frac{1}{\mathrm{p}_{1 \mathrm{f}}}-\frac{1}{\mathrm{p}_{1 \mathrm{i}}}\right) \mathrm{p}_{\mathrm{atm}} \\
\mathrm{W}^{*}=\frac{\mathrm{W}}{\mathrm{n}_{1} \mathrm{RT}}=\ln \left(\frac{\mathrm{p}_{1 \mathrm{i}}}{\mathrm{p}_{1 \mathrm{f}}}\right)-\left(\frac{1}{\mathrm{p}_{1 \mathrm{f}}}-\frac{1}{\mathrm{p}_{1 \mathrm{i}}}\right) \mathrm{p}_{\mathrm{tm}} \\
\mathrm{V}_{\mathrm{T}}=\left(\frac{\mathrm{W}_{0}}{\mathrm{~W}^{*}}\right) \frac{1}{\eta_{\mathrm{T}}}\left[\frac{2}{\mathrm{p}_{1 \mathrm{f}}}-\frac{1}{\mathrm{p}_{1 \mathrm{i}}}\right]
\end{gathered}
$$


The analysis of these equations assumes a fixed value of $\mathrm{p}_{1 \mathrm{i}}, \mathrm{W}_{0}$, and $\eta_{\mathrm{T}}$. The value of $p_{1 f}$ is varied allowing for determination of the final tank pressure associated with the minimum volume and mass.

\subsubsection{Mass estimate for pneumatic/hydraulic one tank system}

The mass of the tanks can be determined by finding the maximum volume and pressure in the tank and the pressure of the hydraulic fluid receptacle.

$$
\mathrm{m}_{\text {Tanks }}=2.25\left(\frac{\mathrm{n}_{1} \mathrm{RT}}{\mathrm{x}_{\mathrm{m}} \mathrm{g}}\right)\left[\frac{2 \mathrm{p}_{1 \mathrm{i}}}{\mathrm{p}_{1 \mathrm{f}}}-\frac{\mathrm{p}_{\mathrm{atm}}}{\mathrm{p}_{1 \mathrm{i}}}\right]
$$

The mass of the gas can be determined by assuming a gas to be used in the system. The tank is assumed to filled with dry air with molar mass MM.

$$
\mathrm{m}_{\mathrm{gas}}=\mathrm{n}_{1} \mathrm{MM}
$$

The mass of hydraulic fluid and the mass of the pump is the same as in 2.1.2. Ignoring any structural addition that would occur in a vehicle system, the total mass of the system is the sum of all the masses. The pump mass is independent of storage as with the two tank system.

$$
\mathrm{m}_{\text {total }}=\mathrm{m}_{\text {Tanks }}+\mathrm{m}_{\text {gas }}+\mathrm{m}_{\text {h.f. }}+\mathrm{m}_{\text {pump }}
$$

\subsection{Efficiency in the pneumatic/hydraulic model}

The efficiency of this system is defined as the ratio of the required work output of the shaft to the input required to return the gas from final conditioning to its original state. The process of returning the gas from final state back to initial state requires the same magnitude of work into the gas as is extracted from the gas, under the idealized assumptions considered here. Therefore, the system turn-around is a function only of the efficiency of the haydraulic pump. The efficiency will be the product of the efficiency of the pump as it adds and during expansion and during recompression. 


\subsection{Pneumatic System}

This system consists of a constant volume tank from which stored high pressure air is expanded through a multistage turbine to extract useful work. As the number of turbine stages increases, it is possible to reduce the mass and volume of stored air, and to increase the turnaround efficiency of the system. The model allows for the possibility that the system may require a second tank for the air to be expanded into in order to meet the design requirements.

\subsection{Pneumatic system model}

The system consists of a high pressure constant volume storage tank from which gas is released at a specified rate and expanded through a number of turbine stages in order to get work from the gas. The outlet of the turbine stages can release gas into a second tank or into the atmosphere. A schematic of the system is provided in Fig. 2. The compression model is the reverse process where the gas is moved from tank 1 to tank 2 and heat is removed from the compressor exhaust. The assumptions used to develop the model are below.

1. One-dimensional flow

2. The process is divided into a number of time steps. Within every time step there is steady flow.

3. Kinetic and Potential energy are negligible

4. Turbine and Compressor stages are adiabatic

5. Working fluid is an ideal gas

6. After each expansion or compression stage a heat exchanger (intercooler or interheater) returns the gas temperature to the inlet temperature of the stage

7. No frictional losses

8. Constant specific heats

9. Each stage has the same compression/expansion ratio

10. Compressors and turbines operate at specified isentropic efficiencies

11. Tank temperature is constant at ambient temperature $(300 \mathrm{~K})$ 


\subsubsection{Pneumatic model for the expansion process}

The first step in the model development is to analyze the turbine stages for their operation in steady state. The total gas release time is $t_{r}$, and for a time step $\Delta t$, the system is considered in steady state. The power output for the system is required to be constant. For $N$ equal time steps, $\Delta t=t_{r} / N$. The ideal (isentropic) work output, $E_{g}$, is the sum of the product of the isentropic power and $\Delta t$. The total work output of the shaft is $E_{0}=\eta_{T} E_{g}$, where $\eta_{\mathrm{T}}$ is the efficiency of each identical turbine stage. So for each finite time period the ideal work of the gas is given by $\Delta \mathrm{W}=\mathrm{E}_{\mathrm{o}} / \eta_{\mathrm{T}} \mathrm{N}$.

The overall isentopic work for the $\mathrm{n}$ stages of expansion for a steady state step with perfect heating between stages is given by the following expression.

$$
\Delta \mathrm{W}=n \Delta \mathrm{m}_{\mathrm{k}} \mathrm{c}_{\mathrm{p}} \mathrm{T}_{0}\left(1-\left(\frac{\mathrm{p}_{2 \mathrm{k}}}{\mathrm{p}_{1 \mathrm{k}}}\right)^{\frac{\gamma-1}{\gamma \mathrm{r}}}\right)
$$

For the kth time step, $\Delta \mathrm{m}_{\mathrm{k}}$ is the change in mass for the time step, $c_{\mathrm{p}}$ is the specific heat of the gas, $\mathrm{T}_{0}$ is the system temperature, $\mathrm{p}_{1 \mathrm{k}}$ and $\mathrm{p}_{2 \mathrm{k}}$ are the overall stage inlet and outlet pressures, and $\gamma$ is the specific heat ratio. The pressures $p_{1 k}$ and $p_{2 k}$ are also assumed to be the pressures in tanks 1 and 2 ( 2 2k would be atmospheric pressure if only a high pressure tank is used). By combining the above expressions the change in mass for a step $\mathrm{k}$ can be developed.

$$
\Delta \mathrm{m}_{\mathrm{k}}=\frac{\mathrm{E}_{\mathrm{o}} / \eta_{\mathrm{T}} \mathrm{N}}{\mathrm{nc}_{\mathrm{p}} \mathrm{T}_{0}\left(1-\left(\frac{\mathrm{p}_{2 \mathrm{k}}}{\mathrm{p}_{1 \mathrm{k}}}\right)^{\frac{\gamma_{-1}}{\gamma_{\mathrm{m}}}}\right)}
$$

The change in pressure can be determined from the ideal gas law as $\Delta p=\Delta m R T / N$. The volumes of tanks 1 and 2 are $V_{1}$ and $V_{2}$, respectively. Using Eq. (18), the change in pressure can be determined for each tank, with $\mathrm{R}$ being the universal gas constant on a mass basis, and $\mathrm{T}_{0}$ the tank gas temperature. 


$$
\mathrm{p}_{1, k+1}=\mathrm{p}_{1 \mathrm{k}}-\Delta \mathrm{m}_{\mathrm{k}} \frac{\mathrm{RT}_{0}}{\mathrm{~V}_{1}}
$$

If the systairem expands to the atmosphere with no second tank, $\mathrm{p}_{2}$ will be constant at atmospheric pressure. If a second tank is used, the pressure in the second tank will change according to the expression below.

$$
\mathrm{p}_{2, \mathrm{k}+1}=\mathrm{p}_{2 \mathrm{k}}+\Delta \mathrm{m}_{\mathrm{k}} \frac{\mathrm{RT}_{0}}{\mathrm{~V}_{2}}
$$

The volumes of tanks 1 and 2 are $V_{1}$ and $V_{2}$, respectively.

\subsubsection{Pneumatic system model for the compression process}

The compression process is developed similarly to the expansion process with $\mathrm{N}$ finite time steady state steps. The work input into the gas per step is $\Delta \mathrm{W}=\mathrm{E}_{\mathrm{in}} \eta_{\mathrm{C} /} \mathrm{N}$, where $\mathrm{E}_{\text {in }}$ is the total input work, and $\eta_{C}$ is the efficiency of each identical turbine stage. The mass and pressure relations are given below.

$$
\begin{gathered}
\Delta \mathrm{m}_{\mathrm{k}}=\frac{\mathrm{E}_{\mathrm{in}} \eta_{\mathrm{C}} / \mathrm{N}}{\mathrm{nc}_{\mathrm{p}} \mathrm{T}_{0}\left(\left(\frac{\mathrm{p}_{1 \mathrm{k}}}{\mathrm{p}_{2 \mathrm{k}}}\right)^{\frac{r-1}{\gamma^{\mathrm{p}}}}-1\right)} \\
\mathrm{p}_{1, \mathrm{k}+1}=\mathrm{p}_{1 \mathrm{k}}+\Delta \mathrm{m}_{\mathrm{k}} \frac{\mathrm{RT}_{0}}{\mathrm{~V}_{1}}
\end{gathered}
$$

If the system contains one tank $\mathrm{p} 2 \mathrm{k}$ will be constant at atmospheric pressure. If two tanks are used, $\mathrm{p}_{2 \mathrm{k}}$ will vary according to the next equation,

$$
\mathrm{p}_{2, \mathrm{k}+1}=\mathrm{p}_{2 \mathrm{k}}-\Delta \mathrm{m}_{\mathrm{i}} \frac{\mathrm{RT}_{0}}{\mathrm{~V}_{2}}
$$




\subsection{Mass estimate for the pneumatic system}

The mass of the system is the sum of the masses of gas, tanks, and machinery. The mass of gas in the system is determined by application of the ideal gas law at the initial conditions. The expression is developed below where $\mathrm{p}_{1 \mathrm{i}}$ and $\mathrm{p}_{2 \mathrm{i}}$ are the initial pressures in each tank.

$$
\mathrm{m}_{\mathrm{gas}}=\frac{\mathrm{p}_{1 \mathrm{i}} \mathrm{V}_{1}}{\mathrm{RT}_{0}}+\frac{\mathrm{p}_{2 \mathrm{i}} \mathrm{V}_{2}}{\mathrm{RT}_{0}}
$$

The mass of the tanks is determined by the relation below.

$$
\mathrm{m}_{\text {Tanks }}=\frac{2.25}{\mathrm{x}_{\mathrm{m}} \mathrm{g}}\left(\mathrm{p}_{1 \mathrm{i}} \mathrm{V}_{1}+\mathrm{p}_{2 \mathrm{f}} \mathrm{V}_{2}\right)
$$

In this equation, $\mathrm{g}$ is the gravitational acceleration, $\mathrm{x}_{\mathrm{m}}$ is the unit of merit for the tank material (a unit of length), and p2f is the final pressure in tank 2 . The 2.25 in the expression is a mandated factor of safety. The mass of the turbine stages, heat exchangers, and the ducting and valving necessary is assumed to be a fixed. The mass of the tanks and gas can be scaled linearly to the energy storage required, while the mass of machinery is constant. Not included is any additional mass required in a vehicle system to support the weight of the system. The expression for the total mass of the system is given below.

$$
\mathrm{m}_{\mathrm{toal}}=\mathrm{m}_{\text {Tanks }}+\mathrm{m}_{\mathrm{gas}}+\mathrm{m}_{\mathrm{machinery}}
$$

Setting $V_{2}$ to zero in the above expressions gives the mass for the one tank system.

\subsection{Application of Pneumatic model and turn-around efficiency}

The model of the system is applied by picking initial pressures for the system, as well as the output work required. The ratio of the volumes of each tank must be picked if two tanks are used. The pressures and mass changes are cālculated for the specified number of time steps. The system volume is minimized by applying a trial and error method to expansion process. This involves picking a volume and checking the Nth time step to see 
if the final pressures are equal. The volume is adjusted so that at the Nth step the two pressures are close to equality without having a higher pressure in the second tank.

The turn-around efficiency is calculated by finding the amount of work required to compress the gas from the final state back to the initial state in the same time as the expansion occurs. The turn-around efficiency of the system is $\mathrm{E}_{0} / \mathrm{E}_{\mathrm{in}}$.

\subsection{Results}

The analysis for this system has the primary goal of finding the minimum mass and volume system required to get a specified output work. For both models the value of energy output scales linearly with mass and volume. Because of this, an energy output of $1 \mathrm{kWh}$ is used as the basis for all calculations. The other results are determined by upon scaling the results to the desired energy storage capacity.

\subsection{Pneumatic/hydraulic model analysis and results}

The analysis is applied to both the one and two tank systems in order to find system chaaracteristics for minimum mass and volume. It is found to be beneficial for all configurations to have the pressure in the high pressure tank to be the maximum possible. This maximum pressure is assumed to be $30126 \mathrm{kPa}$ ( $4500 \mathrm{psi}$ ). Minimum system mass and volume can be achieved with a one tank system. The final pressure in the tank is an important variable in determining system volume and mass. The calculation presented here yields final pressures that result in minimum system volume and mass. Final pressure for minimum system volume was bound to be different than the final pressure for minimum system mass. As the efficiency is solely a function of the turbomachinery and is considered constant, mass and volume do not have any effect on system efficiency. Table 1 shows the results of the analysis for the minimum volume case and minimum mass case for a one tank system. Table 2 contains the results of the analysis for a two tank system operated between $31026 \mathrm{kPa}(4500 \mathrm{psi})$ and $4137 \mathrm{kPa}(600 \mathrm{psi})$. The two tank system is found to be most compact when the final pressures of the tanks are equal $(\beta=1)$. This table is developed for the possibility that the pump may operate more efficiently over a reduced pressure ratio. The minimum volume and mass occur at different molar ratios for the two tank system. 
The tank material assumed is a carbon fiber tank with a unit of merit of $50800 \mathrm{~m}\left(2 \times 10^{6}\right.$ in). This tank has excellent strength to weight characteristics with a cost of $\$ 120 / \mathrm{kg}$. The hydraulic fluid is assumed to have a specific gravity of 0.6 , corresponding to a density of $600 \mathrm{~kg} / \mathrm{m}^{3}$. The pump dry mass of $39 \mathrm{~kg}$ is taken from the Linde's BPV pump specifications, ${ }^{5}$ with additional mass of $6 \mathrm{~kg}$ assumed to adjust for piping, valving, and the pump's internal hydraulic fluid. The tables show the total mass and the volume of the tanks for $7.5 \mathrm{kWh}, 1.0 \mathrm{kWh}$, and $0.1 \mathrm{kWh}$.

\subsection{Pneumatic model analysis and results}

For this system the minimum mass and volume are limited by the amount of storage and the efficiency of the system. The system volume and mass is decreased by having the maximum possible pressure in the high pressure tank. This maximum pressure is $30126 \mathrm{kPa}$ (4500 psi). A reasonable number of turbine stages must be used, and for the purposes of this analysis three stages is considered the maximum reasonable number of stages, due to cost and size considerations. If efficiency considerations are ignored, the analysis of these systems show that minimum volume and minimum mass occur for a one tank system. An efficiency of $75 \%$, necessary to be competitive with batteries, can be reached for minimum volume with a two tank system. In this system the low pressure tank would be initially at atmospheric pressure. Table 3 shows the results for both cases.

The tank for this analysis is assumed to be carbon fiber with a unit of merit of $50800 \mathrm{~m}$ ( $2 \times 10^{6} \mathrm{in}$ ). The turbine/compressor mass is assumed to be a constant $10 \mathrm{~kg}$. The table shows the total mass and the volume of the tanks for $7.5 \mathrm{kWh}, 1.0 \mathrm{kWh}$, and $0.1 \mathrm{kWh}$.

\subsection{Conclusions}

The storage of energy in compressed gases has been analyzed for two configurations. First, a pneumatic system with a hydraulic working fluid, and secondly, a pneumatic system with a gaseous working fluid. Each system has been analyzed for three storage requirements. These requirements are designed to give an estimate of the feasibility of using compressed gas as an energy storage or power assisting device in pneumatic, series hybrid, or conventional vehicles. The requirements for a pneumatic vehicle with a 50 
mile range would be on the order of $7.5 \mathrm{kWh}$ storage. For a series hybrid vehicle the energy storage requirements are on the order of $1.0 \mathrm{kWh}$. Both pneumatic vehicles and series hybrid vehicles storage systems have the additional design constraint that the turnaround efficiency of the storage system must be above $75 \%$ in order to compete with battery storage efficiency. The third possible storage application is as a short duration power device. Such a device could be used for a power assist device on any vehicle. The storage requirement for such a device has been assumed to be on the order of $0.1 \mathrm{kWh}$, allowing for $50 \mathrm{~kW}$ output for 7 seconds. The efficiency of this device is a secondary concern in this application.

The analysis shows that for a $75 \%$ efficient pneumatic vehicle requiring a storage of $7.5 \mathrm{kWh} / 80 \mathrm{~km}$ the minimum volume would be for the purely pneumatic storage model. The tank volume as shown on Table 3 of $1.7 \mathrm{~m}^{3}$ is probably too great to be used in a vehicle. The minimum mass determined for this system also appears too high at slightly under $1000 \mathrm{~kg}$, which approaches the mass of some current conventional automobiles. It is possible to trade-off efficiency for a lower volume and mass, which would result in a reasonably sized system (Table 3 , column 1 ). However, the low turnaround efficiency of this system may result in excessive energy consumption.

For hybrid vehicles the $1.0 \mathrm{kWh}$ requirement is met with minimum mass and volume for the $75 \%$ efficiency constraint by the purely pneumatic storage. From Table 3 the tank volume of the system would be 232 liters and the mass would be $142 \mathrm{~kg}$. The displacement and mass of this system are probably too high for hybrid vehicles.

The $0.1 \mathrm{kWh}$ storage may have application in many vehicle systems. Both the systems shown on Table 1 and Table 3 are of reasonable size for this purpose. The system which works between $30126 \mathrm{kPa}$ and $4137 \mathrm{kPa}$ is too spacious and heavy to be practical in this application. It appears that a pneumatic/hydraulic storage could be built with a mass of 90 $\mathrm{kg}$ and a tank volume of 60 liters. The purely pneumatic system with a mass of $12.4 \mathrm{~kg}$ and 4.8 liters of tank displacement is very reasonable for this system. While the hydraulic 
system appears to be a possibility for this system, the purely pneumatic system is an order of magnitude smaller in both mass and tank displacement. The size of the purely pneumatic system is the most reasonable for this application.

The results presented in this report appear to indicate that the use of compressed gas for energy storage has the best possibility of success for short duration power assist applications. The pneumatic system has the lowest mass and volume, but the pneumatic/hydraulic system could also be made to fit in a vehicle. There are many possible uses for a short duration power assist system. In electric cars, the device could be used to reduce the battery peak power requirements. This could improve battery efficiency and extend its life. A power assist system could also allow for having a smaller engine on a conventional vehicle with this system to back up the engine when power is needed for some short time period. A similar system could be used to accelerate larger vehicles and reduce the emissions associated with the transient engine respónse.

The analysis presented in this report is highly idealized and describes best-case systems. Many other considerations must be accounted for in the next level of analysis. Actual manufacturers data should be used for the turbine and compressor efficiencies, masses, and volumes. The additional volume requirements for machinery also need to be determined. The heat losses from tanks and machinery and temperature variations need to be analyzed. If the system were connected electrically to the vehicle, as probably required for a series hybrid vehicle, there would be additional efficiency losses because the systems would require an additional motor/generator to charge and discharge. This would also increase the mass and volume of the system. More analysis is required to determine whether this system could be developed cheaply, efficiently, and within the mass and volume limitations. 


\section{References}

1. Aceves, Salvador M. and J. Ray Smith, "A Hybrid Vehicle Evaluation Code and its Application to Vehicle Design," SAE Paper 950491.

2. Richard T., "Air Powered Car Rolls Through Joplin, Missouri," Hydraulics and Pneumatics, Aug. 1995, pp 2.

3. Valenti, Michael, "Pneumatic Approach Reduces Emissions," Mechanical Engineering. July 1994, pp 48.

4. Jost, Kevin, "GM's PrEView Impact Electric Vehicle," Automotive Engineering, Feb. 1995, pp 85-89.

5. Linde Hydraulics Corporation, "BPV Variable Displacement, Axial Piston Pumps for Closed-Loop Applications," P/N 8880066406. 


\section{Table 1}

Characteristics of the pneumatic/hydraulic system, for a system with only one pressure storage. Hydraulic fluid expands against atmospheric pressure. The two columns giv characteristics for a minimum volume and for a minimum mass system.

\begin{tabular}{|c|c|c|c|}
\hline & & Minimum Volume & Minimum Mass \\
\hline Initial tank pressure & $\mathrm{kPa}$ & 30126 & 30126 \\
\hline Final tank pressure & $\mathrm{kPa}$ & 14100 & 8100 \\
\hline Pump outlet pressure & $\mathrm{kPa}$ & 101.35 & 101.35 \\
\hline Pump efficiency & & $90 \%$ & $90 \%$ \\
\hline Tank volume per $\mathrm{kWh}$ & liters $/ \mathrm{kWh}$ & 563 & 646 \\
\hline Unit of merit for tank & m (in) & $50800(2 \mathrm{E} 6)$ & $50800(2 \mathrm{E} 6)$ \\
\hline Density of hydraulic fluid & $\mathrm{kg} / \mathrm{m}^{3}$ & 600 & 600 \\
\hline Mass of air per $\mathrm{kWh}$ & $\mathrm{kg} / \mathrm{kWh}$ & 59.7 & 35.0 \\
\hline Mass of tanks per $\mathrm{kWh}$ & $\mathrm{kg} / \mathrm{kWh}$ & 102.1 & 104.2 \\
\hline Mass of hydraulic fluid per $\mathrm{kWh}$ & $\mathrm{kg} / \mathrm{kWh}$ & 318.1 & 281.5 \\
\hline Net mass per $\mathrm{kWh}$ & $\mathrm{kg} / \mathrm{kWh}$ & 479.9 & 420.7 \\
\hline Pump mass & $\mathrm{kg}$ & 45.0 & 45.0 \\
\hline Turnaround efficiency & & $81 \%$ & $81 \%$ \\
\hline \multicolumn{4}{|c|}{$7.5 \mathrm{kWh}$ Storage } \\
\hline Total mass & $\mathrm{kg}$ & 3644.2 & 3200.5 \\
\hline Tank volume & liters & 4222.5 & 4845.0 \\
\hline \multicolumn{4}{|c|}{$1.0 \mathrm{kWh}$ Storage } \\
\hline Total mass & $\mathrm{kg}$ & 524.9 & 465.7 \\
\hline Tank volume & liters & 563.0 & 646.0 \\
\hline \multicolumn{4}{|c|}{$0.1 \mathrm{kWh}$ Storage } \\
\hline Total mass & $\mathrm{kg}$ & 93.0 & 87.1 \\
\hline Tank volume & liters & 56.3 & 64.6 \\
\hline
\end{tabular}




\section{Table 2}

Characteristics of the pneumatic/hydraulic system for a system with two pressure storages. Initial pressures of the two tanks are $30126 \mathrm{pKa}$ and $4137 \mathrm{kPa}$. The two columns give characteristics for a minimum volume and a minimum mass system.

Initial tank 1 pressure

Final tank 1 pressure

Initial tank 2 pressure

Final tank 2 pressure

molar ratio (tank $1 / \operatorname{tank} 2)$

Pump efficiency

Tank volume per $\mathrm{kWh}$

Unit of merit for tank

Density of hydraulic fluid

Mass of air per $\mathrm{kWh}$

Mass of tanks per kWh

Mass of hydraulic fluid per $\mathrm{kWh}$

Net mass per $k W h$

Pump mass

Turnaround efficiency

Total mass

Tank volume

Total mass

Tank volume

Total mass

Tank volume
Minimum Volume

$\mathrm{kPa}$

$\mathrm{kPa}$

$\mathrm{kPa}$

$\mathrm{kPa}$

liters/kWh

$\mathrm{m}$ (in)

$\mathrm{kg} / \mathrm{m}^{3}$

$\mathrm{kg} / \mathrm{kWh}$

$\mathrm{kg} / \mathrm{kWh}$

$\mathrm{kg} / \mathrm{kWh}$

$\mathrm{kg} / \mathrm{kWh}$

$\mathrm{kg}$

$7.5 \mathrm{kWh}$ Storage

$\mathrm{kg}$

11514.8

7110.0

6054.6

liters

$1.0 \mathrm{kWh}$ Storage

$\mathrm{kg}$

1574.3

846.3

liters

948.0

1723.0

12922.5 kg

liters
197.9

$94.8^{\circ--}$
Minimum Mass

30126

7300

4137

101.35

1

90\%

1723

50800 (2E6)

600

105.7

123.6

572.0

801.3

45.0

$81 \%$

\section{$0.1 \mathrm{kWh}$ Storage}

$\begin{array}{ll}\text { gg } & 197.9 \\ \text { liters } & 94.8^{--}\end{array}$

172.3 


\section{Table 3}

Characteristics of the pneumatic system. The two columns describe systems with different constraints. The first column is for a system that meets the energy storage requirements with no concern for sysem efficiency. This system has a single storage tank (Fig. 2(b)). The second column is for a system that meets the requirement of haing a $75 \%$ turnaround efficiency. This system has two tanks (Fig. 2(a)).

\begin{tabular}{|c|c|c|c|}
\hline 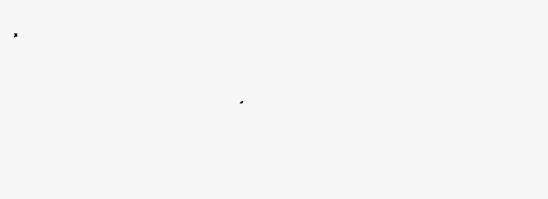 & & $\begin{array}{c}\text { Minimum } \\
\text { mass/volume for } \\
\text { any efficiency }\end{array}$ & $\begin{array}{c}\text { Minimum } \\
\text { mass/volume for } \\
75 \% \text { efficiency }\end{array}$ \\
\hline Initial tank 1 pressure & $\mathrm{kPa}$ & 30126 & 30126 \\
\hline Final tank 1 pressure & $\mathrm{kPa}$ & 160.4 & 16570 \\
\hline Initial tank 2 pressure & $\mathrm{kPa}$ & $\mathrm{n} / \mathrm{a}$ & 101.35 \\
\hline Final tank 2 pressure & $\mathrm{kPa}$ & $\mathrm{n} / \mathrm{a}$ & 14560 \\
\hline Number of turbine/comp stages & & 3 & 3 \\
\hline Turbine/compressor efficiency & & $90 \%$ & $90 \%$ \\
\hline Tank volume per $\mathrm{kWh}$ & liters $/ \mathrm{kWh}$ & 48.1 & 232.0 \\
\hline Unit of merit for tank & $\mathrm{m}$ (in) & 50800 (2E6) & 50800 (2E6) \\
\hline Mass of air per $\mathrm{kWh}$ & $\mathrm{kg} / \mathrm{kWh}$ & 17.3 & 83.9 \\
\hline Mass of tanks per $\mathrm{kWh}$ & $\mathrm{kg} / \mathrm{kWh}$ & 6.7 & 47.8 \\
\hline Net mass per kWh & $\mathrm{kg} / \mathrm{kWh}$ & 24.0 & 131.7 \\
\hline Machinery mass & $\mathrm{kg}$ & 10.0 & 10.0 \\
\hline Turnaround efficiency & & $53 \%$ & $75 \%$ \\
\hline \multicolumn{4}{|c|}{$7.5 \mathrm{kWh}$ Storage } \\
\hline Total mass & $\mathrm{kg}$ & 190.2 & 997.5 \\
\hline Tank volume & liters & 360.8 & 1740.0 \\
\hline \multicolumn{4}{|c|}{$1.0 \mathrm{kWh}$ Storage } \\
\hline Total mass & $\mathrm{kg}$ & 34.0 & 141.7 \\
\hline Tank volume & liters & 48.1 & 232.0 \\
\hline \multicolumn{4}{|c|}{$0.1 \mathrm{kWh}$ Storage } \\
\hline Total mass & $\mathrm{kg}$ & 12.4 & 23.2 \\
\hline Tank volume & liters & 4.8 & 23.2 \\
\hline
\end{tabular}




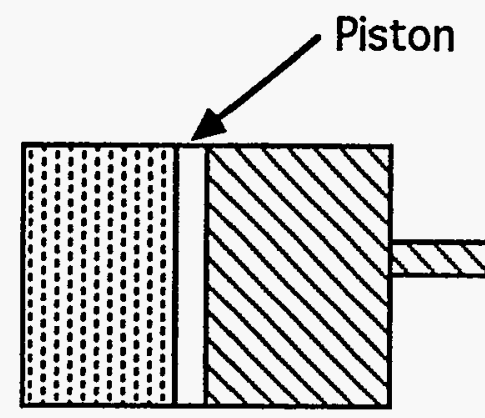

Tank 1

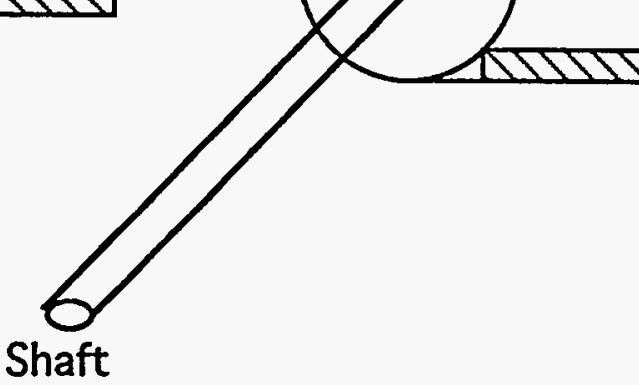

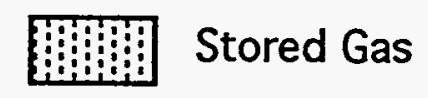

Hydraulic Fluid

Pump

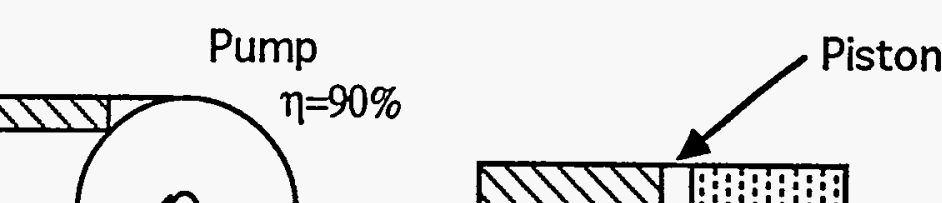

Tank 1

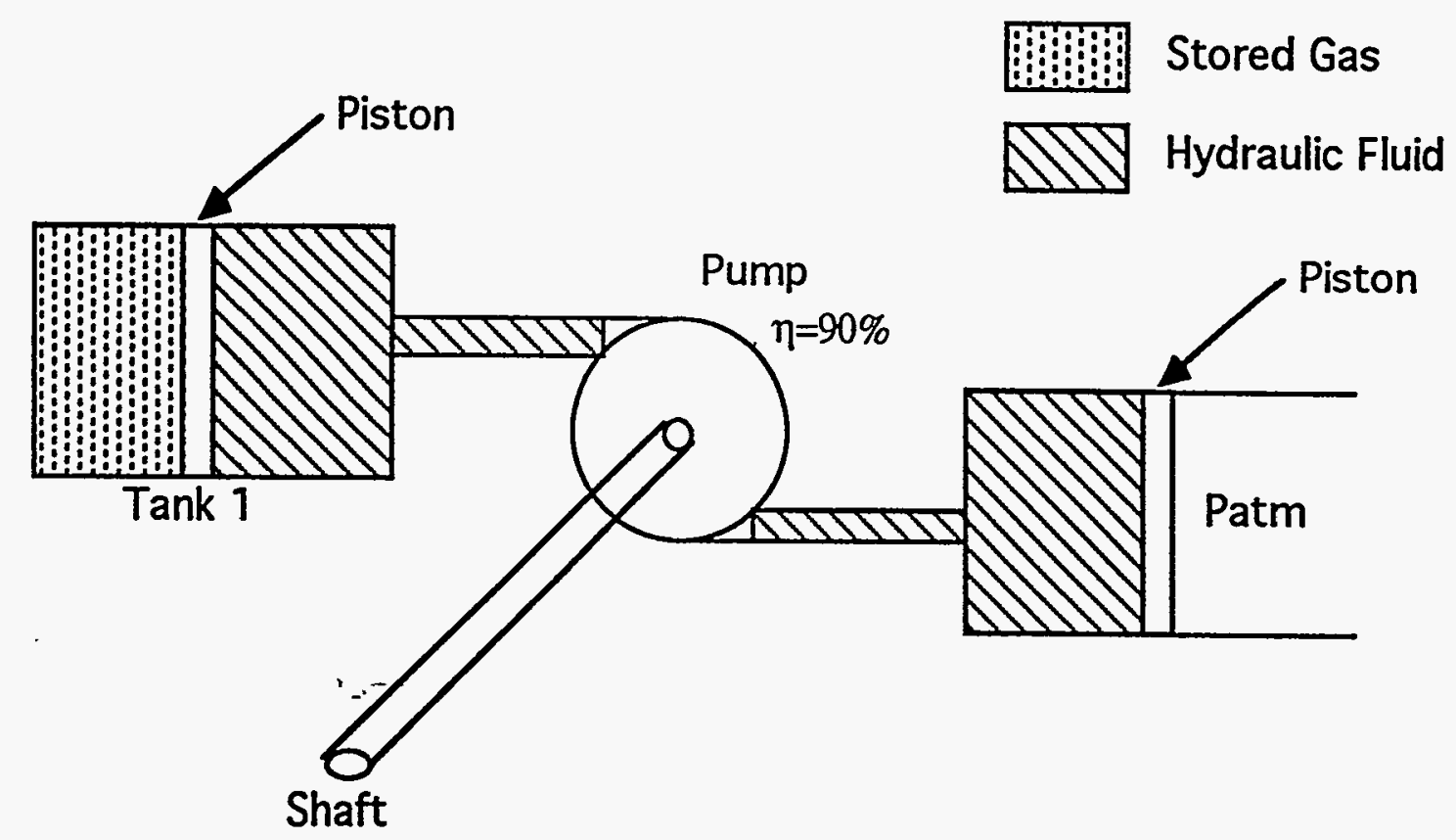

Stored Gas

Figure 1. Schematic of the pneumatic/hydraulic system with two possible configurations: (a) two tank system, and (b) one tank system. 
Figure 2
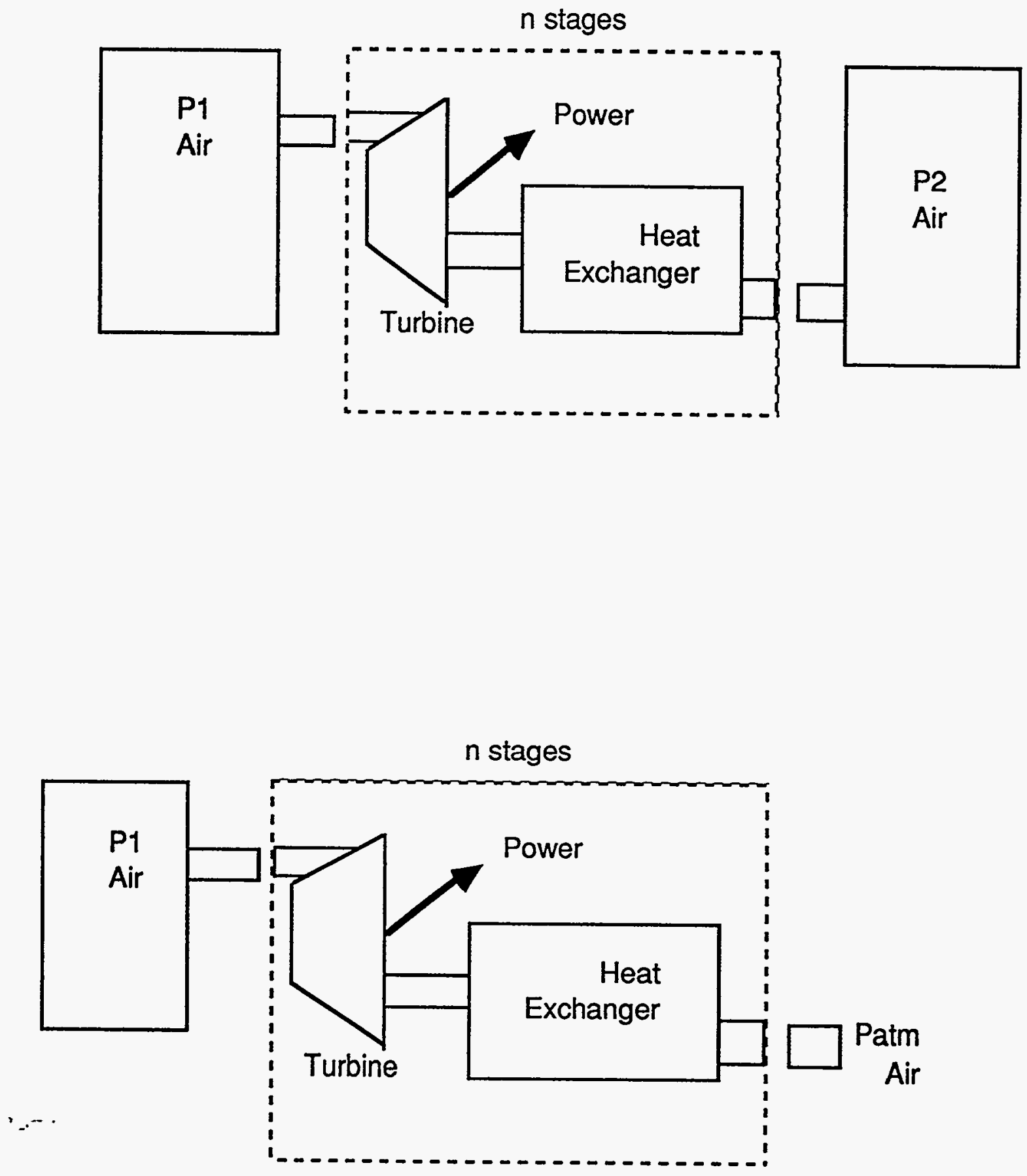

Figure 2. Schematic of the pneumatic system with two possible configurations: (a) two tank system, and (b) one tank system. 


\begin{tabular}{|c|c|}
\hline Nomenclate & \\
\hline$c_{p}$ & specific heat at constant pressure of gas \\
\hline $\mathrm{E}_{\mathrm{g}}$ & ideal gas work \\
\hline $\mathrm{E}_{\mathrm{in}}$ & work input for compression \\
\hline $\mathrm{E}_{\mathrm{o}}$ & required work output for turbine expansion \\
\hline g & acceleration of gravity \\
\hline $\mathrm{m}_{\text {tanks }}$ & mass of tanks \\
\hline $\mathrm{m}_{\mathrm{gas}}$ & mass of gas in tanks \\
\hline $\mathrm{m}_{\mathrm{h} . \mathrm{f} .}$ & mass of hydraulic fluid \\
\hline $\mathrm{m}_{\text {pump }}$ & mass of hydraulic pump \\
\hline $\mathrm{m}_{\text {machinery }}$ & mass of turbomachinery and heat exchangers \\
\hline$\Delta \mathrm{m}_{\mathrm{k}}$ & change in mass for an incremental time step \\
\hline n & number of moles of gas in a tank \\
\hline $\mathrm{n}$ & number of turbine/compressor stages \\
\hline $\mathrm{N}$ & number of time steps \\
\hline $\mathrm{p}$ & tank pressure \\
\hline $\mathbf{R}$ & universal gas constant on a molar basis \\
\hline$\Delta \mathrm{t}$ & time step \\
\hline$t_{\mathbf{r}}$ & total gas release time \\
\hline $\mathrm{T}_{\mathrm{o}}$ & tank temperature \\
\hline $\mathrm{T}$ & system temperature \\
\hline $\mathrm{V}_{\mathrm{T}}$ & Total volume of the tanks \\
\hline W & Work of the process from initial to final states \\
\hline$W^{*}$ & non dimensional work done by the gas for the process \\
\hline $\mathrm{w}_{\mathrm{o}}$ & required output work \\
\hline$\Delta \mathrm{W}$ & ideal gas work for specified time step \\
\hline $\mathbf{x}_{\mathbf{m}}$ & unit of merit for tanks \\
\hline$\alpha$ & ratio of moles in tank $1, \mathrm{n}_{1}$, to moles in tank $2, \mathrm{n}_{2}$ \\
\hline$\beta$ & ratio of the final pressure in tank $1, p_{1 f_{3}}$ to the final pressure in tank $2, p_{2} f$ \\
\hline$\gamma$ & specific heat ratio \\
\hline$\eta_{P}$ & pump efficiency \\
\hline$\eta_{\mathrm{T}}$ & turbine stage efficiency \\
\hline$\eta_{C}$ & compressor stage efficiency \\
\hline
\end{tabular}

